\title{
Medium and Mediators: Tracing Collaborative Authorship
}

\author{
Jesse C. Newman
}

\begin{abstract}
This paper investigates how stylistic decisions of authors can be tracked in the context of the inherently collaborative mediums of film, television and animated serials. In order to measure and evaluate authorial input, dual sets of cases studies in credit taking, inspiration and collaboration are explored and assessed. The jealously credited script writing and concept development of Aaron Sorkin is compared with the more reflexive and pluralistic credit of Japanese animated series authored by 'Sunrise' creative staff under a shared nom de plume of 'Hajime Yatate'.
\end{abstract}

Index Terms-Anime, authorship, collaboration, Shinchiro Watanabe, Sorkin.

\section{INTRODUCTION}

The question can be raised, in the case of collaborative arts, as to whether authorship can be located in the text [1]. Arguably stylistic decisions can be tracked and made visible beyond commercial drives and repetitive genre conventions, and then resituated in the individual and collaborative event. This paper will attempt to locate authorial voice, projection of pet narratives and stylistic trends between two bodies of work. An investigation will be conducted into the film and television productions that list Aaron Sorkin as a writer and into the 1998 animated series 'Cowboy Bebop', in its context in the directorial oeuvre of Shinchiro Watanabe. The argument will be made that authorial actions can be traced. This tracing can be achieved in the case of Cowboy Bebop by locating a text in relation to surrounding works sharing common collaborative creatives. Alternatively it will be demonstrated in the case of Sorkin's early work by analyses of text's forms and structure. Authorship will be investigated as an emergent dynamic, as input can fluctuate as an authorial style takes shape.

\section{COWBOY BEBOP}

\section{A. Bebop Jazz Creations}

The creative method in the conception of characters, settings, music, narrative and performance in the text is tied to that of Bebop Jazz, in which ad-libbing sessions between performers are used to excavate and interrogate melody structures and conventions [2]. This procedure in Jazz was developed to counter mainstreaming of Jazz for dance halls. The music was intentionally produced as content heavy to force reflective listening and engage the listener in artform as artform. The team behind Cowboy Bebop had similar concerns and goals [3].

Manuscript received January 20, 2015; revised March 12, 2016.

J. C. Newman is with the Department of Media, Music, Communication and Cultural Studies at Macquarie University, Sydney, NSW 2109 Australia (e-mail: jesse.newman@students.mq.edu.au).
Cowboy Bebop is the definitive example of the porting of Bebop Jazz procedures to film and animated formats. Genre is emphasised, the interactions of the creatives are spontaneous and de-hierarchised, even the plot itself, the overarching characteristic of serial entertainment, is given a backseat role to structural and aesthetic objectives and considerations. As in Bebop Jazz, the viewer is forced to read the work closely, or risk missing the key concepts and narrative subtleties.

\section{B. A Ghost out of the Corporate Machine}

The central figure in the Bebop project is unquestionably the director, Shinchiro Watanabe. With his career proper starting only a few years prior on 1994's action animated special 'Macross Plus', Watanabe's first project as full director was to be 'Cowboy Bebop' [3]. The 'Macross' entry he codirected was a jetfighter space opera populated with stock characters put forward without apparent irony. As an uncredited reimagining of the 1986 Tom Cruise vehicle 'Top Gun' this loosely connected instalment in the already successful 'Macross' franchise was an experiment in high budget animated action sequences in a Hollywood vein, aimed at direct VHS sales [4].

For Watanabe, being given a secondary 'co-directed' credit to the original 'Macross' series director Shōji Kawamori, seems to have provided the skeleton of a team for his definitive debut in 'Bebop'. The customised musical compositions of Yoko Kanno (with key vocals from Mai Yamane) and the scripting of Kieko Nobumoto, Watanabe's later collaborators, are etched on the Bandai Visual team of Macross. These key creatives would form the engine and inspiration of the Bebop project two years later. Watanabe, Kanno and Nobumoto clearly enjoyed collaborating but chafed at their restrictions in corporatized genre production [3].

The combination in 'Macross Plus' of expensive international market oriented action sequences with inter character driven conflict were the foundation of Watanabe's bankability as a director and foreshadow his later works without engaging in his trademark referential genre fest [5]. Originally slated by corporate decision makers as a future merchandising money spinner, Watanabe was given carte blanche by Bandai's toy making arm to make whatever content he wished so long as it prominently featured a spacecraft. Using this freedom to restructure production to creatively utilise his entire team resulted in unusual, author heavy design and narrative but also risked the production's viability [3].

As the Bebop concept development unfolded, it became clear that this series would not primarily be designed to fuel toy sales. The Macross franchise had been a robot merchandising bonanza, but the Bebop artwork and settings were clearly too whimsical and arthouse to fuel sales of the 'Mecha' merchandising Bandai had built into their production 
model. Following the withdrawal of support of Bandai's toy manufacturing arm it was only the intervention of the animation arm of the corporation that allowed production to commence. Essentially this was a vote of confidence for the creative team of Watanabe as director, Yoko Kanno as composer and Kieko Nobumoto as head writer, the same team that had been so commercially successful with 'Macross Plus' [6].

\section{Hajime Yattate and Shared Authorship}

The staff of the Bebop production company 'Sunrise', took a group credit for series creator, as authorship of an original series is ambiguous across the spectrum of key creatives (Woodmansee, 1994). A collective credit under a 'nom de plume' allows the staff to build a creative identity within the context of an entertainment giant as big as the production house, in this case Bandai Visual. This group credit, used for a number of other 'Sunrise' produced works was 'Hajime Yatate', adapted from a quote of the poet Matsuo Basho, about his own fears of risk taking in art [7].

The distinct character of 'Hajime Yatate's' 'Bebop', can be traced through the dialectic between music, structure and its divergence in form from competitor-produced content. Other texts of the period are more illustrative in their creation. As mass produced corporate content, much of the anime production of the 90s were designed to sell lines of toys, maintain ratings indefinitely and to plugin to pre-existing comic book audiences [7].

These works are dominated by soap operatic endeavours with belaboured conflicts against aliens and rivalries between hyper masculinised male forms [8]. 'Tekkaman Blade', 'Robotech', 'Macross' and 'The Vision of Escaflowne' are essentially pot boiler space operas with minimal introspection and predictable plot points of military and individual failure followed by eventual victory [9]. The music, dialogue and art are purely illustrative of their pre-established creative trajectories, as such each component is produced chronologically and independently and cannot feed on the other organically. The giant robot battles that dominate the plots are centre stage, with violence, gore and explosive action overwhelming other aspects of the text. Character development is only given opportunity to provide a spare narrative arc and as time filler dialogue between expensive animation sequences [9].

Bebop represents an alternative direction, presaged by the philosophical spirals of the 1995 auteur serial 'Neon Genesis Evangelion' created by Hideaki Anno, another visionary creative to start his career in the 'Macross' franchise. The massive critical and merchandising success of the inscrutable dystopian philosophy of 'Evangelion' undoubtedly assisted 'Bebop' in receiving a green light for production. 'Bebop' has action components as does 'Evangelion', but is structurally a significantly more haphazard creation, straddling as it does multiple genres. Some 'sessions' are played for comedy, some are subservient to a musical score and others are just frozen in space, the characters inertia mirroring the creative struggle of the freelance artists producing the series.

\section{Bebop and Nonlinear Characteristics}

The staff of the Bebop production company 'Sunrise', took a group credit for the series 'Hajime Yattate' reflecting a body of work produced by that team but also used by Sunrise for a number of its projects. 'Cowboy Bebop' stands alone in both its creative mode of production and correspondingly its resulting form. Character designer Toshihiro Kawamoto was sent back by the executive creative team for constant redesigns as the creative process was unhooked from the linear production procedure of most studio endeavors [10]. Hajime Yattate did not start with a script, or even a writer and director dreaming up a concept together and then asking the team to realise it. Rather creation took place in a dialogue, with visual, musical and directorial conversations interacting in the creation of a unique textual world.

One of its key characters, the androgynous preteen computer hacker 'Edward' was based on the production antics and physicality of series composer Yoko Kanno. A corgi was included due to the illustrator, Kawamoto's ownership of a dog of that breed [11]. Settings were created to match music composed by Yoko Kanno's production band 'The Seatbelts' whom at other points in the production created music to match plot points pushed by Watanbe or Nobumoto or adlibbed in response to graphics or discussions [10].

The setting of the series was also created using this interactive flair in fusing space punk tropes and references to Kubrick and Ridley Scott films. Disjunctive planetscapes rotate as settings for episodes resembling 1980's New York, 1970's Hong Kong and 1990's Tokyo, these open up for reference the visual and narrative bank of the cinema of these periods and locations with which the creative team were keen to experiment. The intertextual and fluid nature of the 'Bebop' world avoids closing it off to plot convention but makes the experience of watching bewildering, with viewers unsure where the author wishes to place emphasis or whether the references are genre work or homage or both.

Analogue television programming occupies this mishmash space alongside casual interplanetary travel. Newstainment and bounty hunting gameshows occupy the faked media space and mock the camper aspects of costuming and genre excess in the series. A hyper inflated fictional currency detaches value from gambling debts, bounty hunters and food prices. In Cowboy Bebop a meal in a restaurant can outstrip the cost of fuelling a spacecraft the size of a house. The authorship of the work in these cases almost overturns the viability of the form as entertainment, ironically the genre tropes hold the work together with the viewer responding to the familiar rather than unfamiliar aspects offered up by Hajime Yattate.

Coming out of this process both 'Cowboy Bebop' and its feature film are characterised by the interrogation of their own artificiality. The landmark animated film of 1995 "The Ghost in the Shell" which in its very title references the 'Deus Ex Machina' or 'God in the Machine', approached questions of perception and artifice directly, but within a strict dystopian genre [12]. Bebop in contrast to this, stresses its genre through third wall breaking, disregard for pace, emphasis on form over function and numerous other techniques which draw attention to the structural composition of the work and the viewers role in its perception.

\section{E. The Mean Streets of Genre}

Bebop has the most in common with late film noir texts such as 1974's 'Chinatown' and 1982's 'Blade Runner'. 
These cynical texts exist within a rich genre vocabulary whilst deriving traction and aesthetic riffs from audience filmic fluency. In the context of Bebop, the protagonist Spike Spiegel is plainly a portage of well-known iconic figures. Practicing the 'Jeet Kun Do' martial arts of Bruce Lee, wearing the boots and brash attitude of Lupin the Third and the humour of Chow Yun Fat's 'God of Gamblers' character, Spiegel was designed as a heroic reimaging of Watanabe [9].

Much like other characters in the series, Spiegel is a self-consciously creative artifice, with little effort to ground him in his own history, he only gains dimensionality through flash backs and narrative structures associated with the backstories of the characters from which he is derived [13]. Spike is apparently little more than an avatar, an assemblage of character attributes with no distinguishable existential factor of his own. Nevertheless as the series progress the naturalising function of readership fills him in like a colouring book, Spike takes on the characteristics the viewer chooses to project and the estrangement caused by such glaring pastiche recedes into the flow of the narrative arc.

\section{AARON SORKIN}

\section{A. Sorkin Astride the Text}

The work of Aaron Sorkin represents an alternative approach to collaboration in authorship, rich with parallels and contradictions to that of Shinichiro Watanabe and Cowboy Bebop. Characterised by protracted monologues, preachy elitist archetypes and professionals justified by their noble callings, the work has similar characteristics in that the author's mark is apparent throughout the text. Furthermore the texts are fluid and self-aware, intersecting with public figures, histories and events.

Sorkin has become a favourite writer for hire of Silicon Valley origin stories; adapting both Mark Zuckerberg's pathos for film in the 2010 'Social Network' and more recently 2015 's 'Steve Jobs'. Both character types feeding on Sorkin's own personal mythos of the failing and flailing genius. The Jobs story highlights his interpersonal conflicts in his pursuit of business idealism and in the case of Zuckerberg a traitorousness and precocity are emphasised in the entrepreneur's conquest of the intimate spaces of social media [14].

It is unclear however if Sorkin selected such works as a preference suiting his authorial approach, or was chosen for a distinctive style or 'brand' matching the repeated story arc of these verbose savants, whose work explodes their personal relations. Sorkin's own tumultuous career, divorce, and drug record mirror these events and clearly fed into the body of work that led to adapting biographies of characters not of his original invention [15].

With initial success coming from the sale of the film rights to his stage play 'A Few Good Men' the opportunity to adapt this work was his initial foray into writing for the screen and the origins of the work are plain in its realisation in film form. Long scenes, monologues, tense courtroom settings, dialogue before and after key events take place off-screen. The film screams out its stage pedigree, but in spite of this succeeded both commercially and critically. Sorkin was rewarded for its stagey nature and in subsequent texts retained and played with such stylistic conventions.

\section{B. The American President and the Casting Call for Typecasting}

Continuing writing on contract for Castle Rock entertainment, as he had on 'A Few Good Men', Sorkin wrote a treatment for Robert Redford's pitch; 'the president elopes', marrying the political with the personal. This concept developed into one of the constant themes in Sorkin's works, of the friction between the high pressure life of prominent professionals, and their fracturing and buckled private lives [16]. The resulting film directed by Rob Reiner is more predictive of Sorkin's future work than that of Reiner's and was credited by critics as anomalous amongst Reiner's work of the period as it attracted acclaim. This critical praise is tribute to the dominant role of Sorkin's writing in Reiner's directorial product.

'The American President', 1995, introduced a cast of archetypes and interrelationships that recur constantly in Sorkin's later television works. The sharp tongued but noble and misunderstood authority figure emerges from Jack Nicholson's Colonel Jessup of 'A Few Good Men' in a more sympathetic light. In the case of 'The American President' this figure becomes Michael Douglas's President Shephard and later in 'Sportsnight' the role is taken on by the dual leads of Co Anchors Dan Rydell and Casey McCall. This flawed protagonist, some sort of manifestation of Sorkin's superego also takes form in Bradley Whitford's Danny Tripp in 'Studio 60 on the Sunset Strip' and Jeff Daniels' news anchor in "The Newsroom."

Characterisation gets particularly incestuous when Sorkin's most renowned Television series 'The West Wing' was born from the script overwrites of 'The American President'. Reaching into the characters created in part by the performances of Micheal J Fox and Michael Douglas, The West Wing involved a fleshing out and recasting of these roles with secondary actors from 'The American President'. Martin Sheen, who played the secretary of state in the film takes on the role of the president, and Joshua Malina who played a hapless researcher in the film, played a hapless researcher in 'Sportsnight' and is cast a third time as a hapless speechwriter in the third season of 'The West Wing [16].

\section{Talking to Himself and always Right}

The actor round table positions Sorkin's subject matter and rotating casts as a palette onto which he plays out pet narratives and his own personal grievances and obsessions. Most glaringly his ambivalence to women's agency and intelligence recurs in all his texts. The most recurrent plot function involves his unconsciously misogynist hero being oppressed by a representative of the cultural police (Christian right wing, nationalists, Mothers for America) embodied in the form of an attractive young woman. This young woman is exposed as being in error within the text, often on a technicality or due to a contrived faux pas. Following this public error of manners the misogynist protagonist must then be apologised to by the women in question [17]. This allows the Sorkin avatar to act benevolently whilst being redeemed for his own errors and mistakes by the nobility of his 'work', whether as a President, news reader, writer or tech CEO [18]. 
Jeff Daniels speech at the centre of 2012's 'The Newsroom' premiere is an exemplar of this artificial fantasy space in which Sorkin is able to argue all sides of public debate and express his frustrated misogyny. Jeff Daniels' news anchor character is placed on a literal podium and asked a question about American greatness by an undergraduate female student, a common straw man in Sorkin texts. The student represents naivety, feminine gullibility and provides a character from whom approval and adoration can be won by the Sorkin representative of the text at hand.

Such a correlation could be explained away as standard rehashing of genre conventions or the creation of star vehicles for authoritative male figures or even just a common case of the best lines going to the stars [16]. This does not sufficiently refute a case that this is an authorial marker. It seems more likely that due to the patterns and habits identifiable across the shifting cast of lead male roles and the centrality of their character to the plot and moral dimension of each text, this is an exercise of first contingency and later agency. Sorkin finds characters in texts he builds collaboratively with actors and producers and then renters these characters with different faces and in different genres, taking over ownership of the collaborative event.

\section{Contingency and Agency in Archetypes}

Sorkin's rise to the spotlight is part and parcel of his later style, and the collaborative nature of those early career teams seems to have imprinted on his creative patterns. Furthermore, his style has had impacts in motivating the careers and opportunities of those with whom he has worked. This style is particularly notable for its verbose dialogue, following collaboration with the Television Producer Thomas Shlamme this would take the form of a 'walk and talk'. This Sorkin/Shlamme trademark later taken on by Sorkin on other projects is a bridging scene in which exposition between characters is delivered whilst a tracking camera follows them from one setting to the next. This matches Sorkin's philosophical proposition of the nobility of high powered jobs and tendency to preach and to plan his television work with characteristics of the stage.

An additional indicator of Sorkin's centrality to the character of the text is the trajectory of the West Wing following his departure [19]. Following a fallout with executives the majority of the team remained and the program continued for a further three seasons sans Sorkin's input. This version of the program falls into a hole immediately after his departure, possibly to his unwillingness to share process or input with his support writers heretofore [20]. It is only with the seventh and final series the show regained coherency and critical acclaim with the injection of big star actors such as Jimmy Smits and Alan Alda. Sorkin hallmarks such as the monologue, the artificial apology and the walk and talk are still present, but recede somewhat to make room for a more conventional team and star driven narrative [19].

\section{WATANABE VS SORKIN}

Watanabe's body of work is characterized by collaborative process and the distinct stylistic features coming out of this. In the case of 'Cowboy Bebop' Watanabe was reforming with the team of 'Macross Plus' to create a superlative creative product intended explicitly to be viewed favourably thirty years into the future. The Bebop project represented a stark contrast to the genre compliant franchise work of 'Macross', in its formation between the creative practice of diverse collaborators.

Similarly, Sorkin has acquired key collaborators throughout his career, with their input not leaving the work following their departure from his programs, but being built upon with new actors or producers and further referenced in the texts [21]. The thematic obsession with the character of the abrasive genius, which is the central tenement across Sorkin's work, is matched apparently in his own career [15]. Jealously grasping at full authorial credit, Sorkin has struggled to share acclaim for his work in spite of his use in television of a writers' room and his co-crediting [22].

Infamously, 'The West Wing' episode 'In Excelsis Deo' which won an Emmy in 1999 for best writing saw only Sorkin ascend the stage to accept the award despite Cleveland's co-credit [23]. The key plotline being based upon the death of Cleveland's father as a homeless, veteran, alcoholic indicates Sorkin may have been over-crediting himself when posting on a West Wing fan website that all Season One episodes of The West Wing were solely authored by him with other writers only credited as a 'gratuity'; supposedly because they fulfilled sounding board or researcher functions in the production [22]. As a creator, Sorkin is willing to take credit for writing adaptations of others' stories but not to acknowledge secondary or support writers.

Sorkin's work, much like the key authorial feature of 'Cowboy Bebop', is its characteristic of being in some ways overwrought [24]. This formalist characteristic in which the hand of the author is jarringly present seems to have evolved from a contingent issue in adaption into his hallmark. In the cases of 'A Few Good Men' or 'The West Wing' the emphasis on 'walk and talk', the personification of Sorkin's own attitudes and relationships and the fantasy of always having the last word are made real and given centre stage.

\section{CONCLUSION}

Conclusively, both texts allow the identification and extraction of author specific textual characteristics, whilst the role of contingency and the role of agency in their development is slippery and dissoluble. In the case of the collaboration that became Cowboy Bebop, the work looks, sounds and feels different from its contemporaries, who employed more hierarchical production methods. Respectively in Sorkin's works, he imposes his personal philosophical hang-ups and language conventions, and is subsequently sought out to author and adapt works that match this style. The outcome is clear that even in production or collaborative settings, the mark of the author or authors can be traced, but only as a relative characteristic against the rest of their body of work and other works comparable in style and target market.

\section{ACKNOWLEDGMENT}

The author would like to thanks Professor John Potts for his feedback and research advice. 


\section{REFERENCES}

[1] M. Woodmansee, "On the author effect: Recovering collectivity," in The Construction of Authorship, M. W. P. Jaszi, Ed. London: Duke University Press, 1994, pp. 15-28.

[2] J. Sevakis. (2013). Shinichiro Watanabe focus panel. Anime News Network. [Online]. Available: http://www.animenewsnetwork.com/convention/2013/otakon/7

[3] A. Suskind. (2014). Asteroid blues: The lasting legacy of Cowboy Bebop. The Atlantic. [Online]. Available: http://www.theatlantic.com/entertainment/archive/2014/12/asteroid-b lues-the-lasting-legacy-of-cowboy-bebop/383817/

[4] L. Cubbison, "Anime fans, DVDs and the authentic text," The Velvet Light Trap, vol. 56, pp. 45-57, 2005.

[5] A. Cooper-Chen, "Cartoon planet: The cross-cultural acceptance of Japanese animation," Asian Journal of Communication, vol. 22, no. 1 , pp. 44-57, May 2012.

[6] Cowboy Bebop' director Watanabe talks anime. (2009). [Online]. Available: http://web.archive.org/web/20090715113817/http://www.dailytexano nline.com/life-arts/cowboy-bebop-director-watanabe-talks-anime-1.9 71462

[7] J. Oppliger. (2003). Ask John: Who is Hajime Yadate? Anime Nation. [Online]. Available: http://www.animenation.net/blog/2003/06/05/ask-john-who-is-hajime -yadate/

[8] M. Hiramoto, "Hey, you're a girl? Gendered expressions in the popular anime, Cowboy Bebop," Multilingua, vol. 32, pp. 51-78, 2013.

[9] M. Douglas. (2010). Cowboy Bebop Review. [Online]. Available: http://www.isugoi.com/cowboy-bebop-review/

[10] Anonymous. (2002). The director's voice | Shinichiro Watanabe interview. [Online]. Available: http://web.archive.org/web/20030307023145/www.cowboybebop.org /english/door/interview/index.html

[11] D. Scally et al., "Interview with Murase Shūkō and Satō Dai," Mechademia, vol. 4, pp. 329-334, 2009.

[12] B. Ruh, "Historicizing anime and manga: From Japan to the world," Mechademia Emerging Worlds of Anime and Manga, vol. 1, pp. 180-183, 2006.

[13] W. Benzon, "Postmodern is old hat: Samurai Champloo," Mechademia, vol. 3, pp. 271-274, 2008.

[14] C. Marx , K. Infante, and R. Murphy, "The social network," Journal of Feminist Family Therapy, vol. 24, no. 2, pp. 179-182, April 2012.

[15] J. Adalian. (2003). Sorkin sulking away from 'Wing'. Variety. [Online].

Available: http://variety.com/2003/scene/news/sorkin-sulking-away-from-wing$1117885506 /$

[16] J. Simmons. (2008). In presidential campaign, life imitates TV. Politico. [Online]. Available: http://www.politico.com/story/2008/02/in-presidential-campaign-lifeimitates-tv-008567
[17] C. Painter and P. Ferruci, "Unprofessional, ineffective, and weak: A textual analysis of the portrayal of female journalists on sports night," Journal of Mass Media Ethics, vol. 27, pp. 248-262, 2012.

[18] D. Margolin, "I love my country: Freedom of speech, Aaron Sorkin, Elie Wiesel,” The Drama Review, vol. 55, no. 3, pp. 153-155, 2011.

[19] M. Ryan. (2006). Aaron Sorkin speaks about 'Studio 60,' the press and those Pesky Bloggers. Chicago Tribune. [Online]. Available: http://featuresblogs.chicagotribune.com/entertainment_tv/2007/01/aa ron_sorkin_sp.html

[20] B. Keveney. (2006). 'West Wing' to end with new president. USA Today. [Online]. Available: http://usatoday30.usatoday.com/life/television/news/2006-01-22-west -wing-canceled_x.htm

[21] G. L. Dillon, "Miindiwag and indigenous diaspora: Eden Robinson's and Celu Amberstones Forays into "Postcolonial" science fiction and fantasy," Extrapolation, pp. 220-243, 2007.

[22] J. Rutenberg, (2001). TV Notes - Sorkin Arrested. The New York Times. [Online]. Available: http://www.nytimes.com/2001/04/18/arts/tv-notes-sorkin-arrested.ht $\mathrm{ml}$

[23] B. Weinraub. (2001). 'West Wing' producer, a union leader, rules out writers' raises. The New York Times. [Online]. Available: http://www.nytimes.com/2001/06/26/arts/west-wing-producer-a-unio n-leader-rules-out-writers-raises.html?pagewanted=all

[24] T. Fahy, "Considering Aaron Sorkin: Essays on the politics, poetics and sleight of hand in the films and television series," International Journal Of Communication, vol. 5, pp. 644-650, 2011.

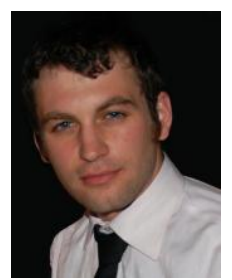

Jesse C Newman was born in the Blue Mountains of Australia, he is currently a candidate for the masters research in security studies, in Macquarie University, Sydney, Australia since 2016.

He has completed a masters of arts degree in politics from University of Wollongong Australia in 2009 and a bachelor of arts/bachelor of creative arts degree, from University of Wollongong, Australia, 2006. He is currently an associate lecturer in cultural studies and Australian studies at the University of Technology Sydney — Insearch. In 2015, he was employed as a research assistant to the Head of School History and Politics, Macquarie University and was a unit convener and developer in 2011 to 2015, Macquarie University, Foundation Program in Society and Culture and Tertiary Research Skills. He was also sponsored to give a series of lectures on Chinese political economy in Sao Paulo Brazil at the Faculdades Rio Branco in 2012. He is interested in research in neo confucian narratives, Asian cinema, ancient Chinese writings and global political economy.

Mr. Jesse Newman is a recipient of the MRES Scholarship at Macquarie University 2016. 